\title{
Challenges in pulmonary hypertension: managing the unexpected
}

\author{
Karen M. Olsson ${ }^{1}$ and Massimiliano Palazzini ${ }^{2}$ \\ Affiliations: ${ }^{1}$ Dept of Respiratory Medicine, Hannover Medical School, Hannover, Germany. ${ }^{2}$ Dept of \\ Specialised, Experimental, and Diagnostic Medicine, University of Bologna, Bologna, Italy.
}

Correspondence: Karen M. Olsson, Dept of Respiratory Medicine, Hannover Medical School, Carl-NeubergStr. 1, 30625 Hannover, Germany. E-mail: Olsson.Karenamh-hannover.de

ABSTRACT The diverse challenges associated with diagnosis and management of patients with pulmonary hypertension are illustrated in this case-based review. Case 1 describes a patient diagnosed with pulmonary arterial hypertension (PAH) with right heart failure and active systemic lupus erythematosus who was effectively treated with an up-front triple combination of PAH therapies and immunosuppressive therapy. In case 2, a diagnosis of pulmonary veno-occlusive disease was reached after a combined approach of clinical suspicion, physical examination, and invasive and noninvasive tests. Cautious PAH therapy and high-dose diuretics provided clinical benefit in this patient and served as a bridge to lung transplantation. These cases highlight the need for ongoing follow-up of patients with $\mathrm{PAH}$, comprising frequent assessment of treatment success and continued diagnostic evaluation.

0 $@$ ERSpublications

Challenging cases of $\mathrm{PH}$ patients highlight the need for appropriate diagnosis and elaborate management http://ow.ly/TCvYd

\section{Introduction}

Significant efforts to improve the diagnosis and classification of pulmonary hypertension ( $\mathrm{PH}$ ) are exemplified by evolving recommendations from the joint task force of the European Society of Cardiology and the European Respiratory Society $[1,2]$. According to these recommendations, PH is divided into five subgroups: pulmonary arterial hypertension (PAH) (group 1); $\mathrm{PH}$ due to left heart disease (group 2); $\mathrm{PH}$ due to lung diseases and/or hypoxia (group 3); chronic thromboembolic pulmonary hypertension and other pulmonary artery obstructions (group 4); and PH with unclear multifactorial mechanisms (group 5) $[1,2]$. Despite the attention that PH has drawn in recent years, significant gaps remain in the evidence-based management of rare and challenging cases of PH. In this case-based review, our aim is to discuss two case studies presented during the 2015 14th International Pulmonary Hypertension Forum in Copenhagen, Denmark, as key examples of the diverse clinical challenges faced when diagnosing and managing patients with $\mathrm{PH}$.

\section{Case 1}

A complex case of PAH with active systemic lupus erythematosus and right heart failure

Cardiac involvement, especially the development of $\mathrm{PAH}$, is a known manifestation in patients diagnosed with active systemic lupus erythematosus (SLE) $[3,4]$. Among patients with SLE, PAH has been reported to occur at rates of $4.2-43.0 \%$ [5-7], with the wide variation in prevalence likely to be attributable to variability in the studied populations, differing diagnostic methods (echocardiography versus right heart catheterisation (RHC)) and inconsistencies in the definition of PAH in earlier studies [3, 4].

Received: Aug 212015 | Accepted after revision: Oct 122015

Conflict of interest: Disclosures can be found alongside the online version of this article at err.ersjournals.com

Provenance: Publication of this peer-reviewed article was sponsored by Actelion Pharmaceuticals Ltd, Allschwil, Switzerland (principal sponsor, European Respiratory Review issue 138).

Copyright CERS 2015. ERR articles are open access and distributed under the terms of the Creative Commons Attribution Non-Commercial Licence 4.0. 
A 28-year-old female presented to the clinic in March 2014 following a cardiologist referral for suspected right heart failure. Prior to admission, the patient had experienced progressive dyspnoea (World Health Organization functional class (WHO FC) IV) and oedema, and signs of severe PH were evident from the echocardiography that was performed. She had previously been diagnosed with SLE (with arthritis and nephritis) in 2005, from which she achieved remission on a treatment regimen of steroids and hydroxychloroquine. On admission, a physical examination of the patient identified a typical butterfly rash, hypotension, tachycardia, a systolic murmur on the left parasternal border and severe oedema. Subsequent laboratory tests suggested the presence of right heart failure and active SLE (elevation of $\mathrm{N}$-terminal pro-brain natriuretic peptide, creatinine and cholestatic parameters, the presence of antinuclear antibodies, and reduced complement levels), while arterial blood gas analysis indicated severe hypoventilation (carbon dioxide tension: $29 \mathrm{mmHg}$ ) and mildly elevated lactate levels $\left(2.5 \mathrm{mmol} \cdot \mathrm{L}^{-1}\right.$ ). An array of imaging tests (radiography, computed tomography (CT) and echocardiography) were then performed, which revealed an enlarged heart, signs of severe $\mathrm{PH}$, severely impaired right heart function and the absence of a pulmonary embolism or parenchymal abnormalities (fig. 1a and b).

Echocardiography showed a markedly dilated right ventricle (right ventricular (RV) end-diastolic diameter: $59 \mathrm{~mm}$ ), a reduced tricuspid annular plane systolic excursion (TAPSE) $(13 \mathrm{~mm}$ ), an elevated tricuspid systolic pressure gradient of $85 \mathrm{mmHg}$, a severe tricuspid insufficiency, a nonhaemodynamic relevant pericardial effusion, and a dilated vena cava inferior. Consequently, haemodynamic evaluation by RHC verified RV failure according to the presence of severe pre-capillary $\mathrm{PH}$, elevated filling pressure, high pulmonary vascular resistance (PVR) and low mixed venous oxygen saturation $\left(\mathrm{S}_{2}\right)$ (table 1). As a result, the patient's diagnosis was confirmed as new-onset (i.e. no history of previous occurrence) PAH with right heart failure and active SLE.

Once diagnosed, the patient was initiated on immunosuppressive therapy (including cyclophosphamide, high-dose corticosteroids and three courses of plasmapheresis), intravenous diuretics (furosemide), low-dose dobutamine and an up-front triple combination of PAH therapies, comprising i.v. iloprost $\left(1.2 \mathrm{ng} \cdot \mathrm{kg}^{-1} \cdot \mathrm{min}^{-1}\right)$, oral sildenafil (20 mg three times daily) and oral macitentan $\left(10 \mathrm{mg} \cdot \mathrm{day}^{-1}\right)$. Following treatment initiation, she
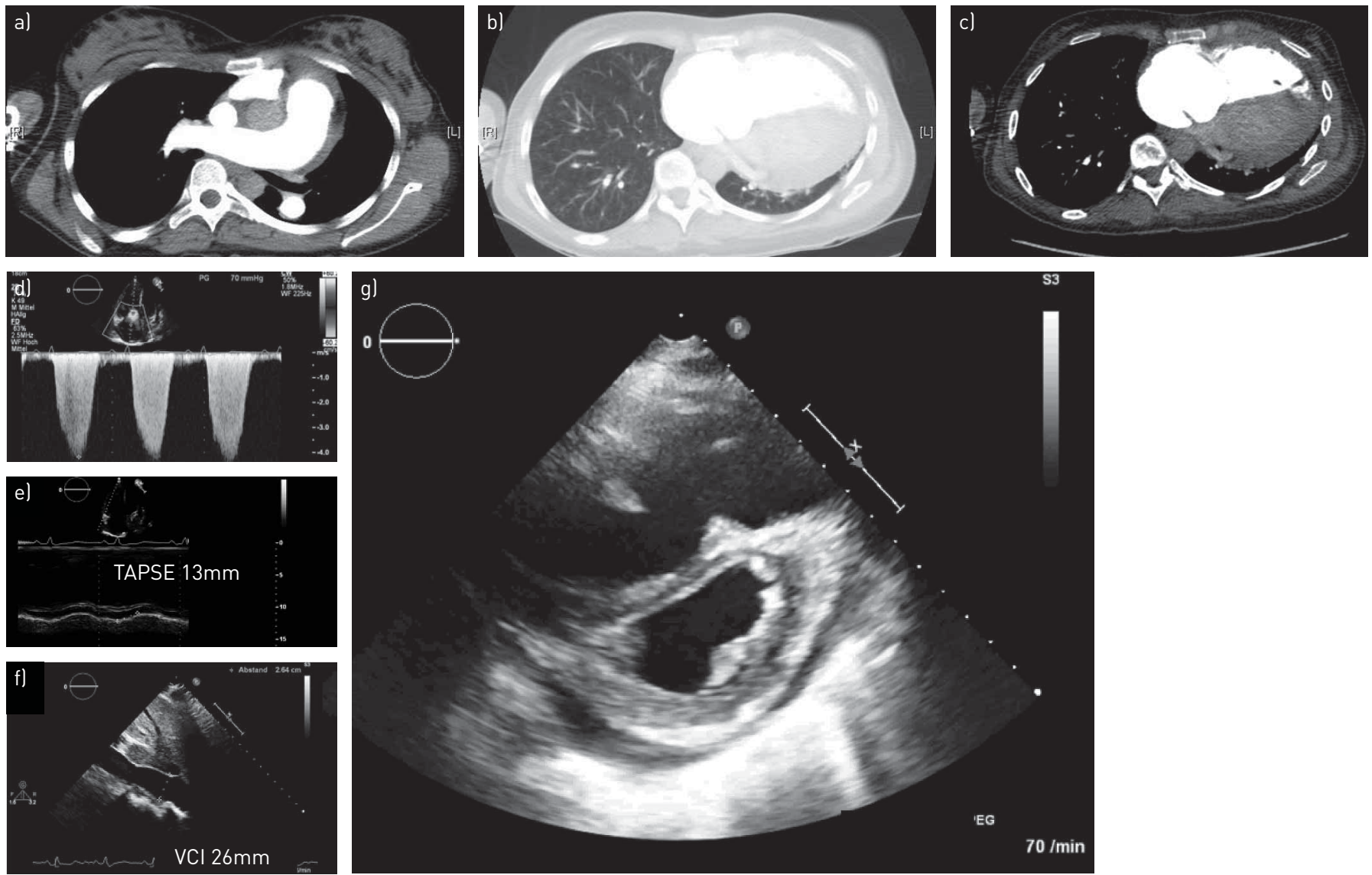

FIGURE $1 \mathrm{a}-\mathrm{c}$ ) Chest computed tomography excluding acute lung embolism and parenchymal lung disease and d-g) echocardiography performed during diagnostic work-up in a patient with pulmonary arterial hypertension with right heart failure and active systemic lupus erythematosus (case study 1). d) Elevated tricuspid regurgitant jet velocity; e) reduced TAPSE; f) dilated VCI. TAPSE: tricuspid annular plane systolic excursion; $\mathrm{VCl}$ : vena cava inferior. 
TABLE 1 Haemodynamic parameters during diagnostic evaluation with RHC in a patient with $\mathrm{PAH}$ with right heart failure and active SLE (case study 1)

\begin{tabular}{|c|c|}
\hline Haemodynamic variable & Measurement \\
\hline Right atrial pressure $\mathrm{mmHg}$ & 19 \\
\hline Mean pulmonary arterial pressure $\mathrm{mmHg}$ & 60 \\
\hline Pulmonary capillary wedge pressure $\mathrm{mmHg}$ & 12 \\
\hline Cardiac index $L \cdot \min ^{-1} \cdot \mathrm{m}^{-2}$ & 1.4 \\
\hline Pulmonary vascular resistance dyn $\cdot \mathrm{s} \cdot \mathrm{cm}^{-5}$ & 1598 \\
\hline $\mathrm{SvO}_{2} \%$ & 34 \\
\hline Vasoreactivity test & Not performed \\
\hline
\end{tabular}

RHC: right heart catheterisation; PAH: pulmonary arterial hypertension; SLE: systemic lupus erythematosus; $\mathrm{SvO}_{2}$ : mixed-venous oxygen saturation.

experienced rapid clinical improvement and was subsequently discharged from hospital after 14 days on a regimen of prednisolone and triple-combination PAH therapy with scheduled admissions for cyclophosphamide pulse treatment at approximately monthly intervals. Examination at 1 and 2 months post-treatment initiation confirmed continued improvement whereby the patient showed regressive signs of $\mathrm{PH}$ on the echocardiogram and no clinical or laboratory indication of active SLE. The PAH therapy was reduced to a double combination of sildenafil and macitentan after the patient presented with a fever associated with the central venous line for i.v. iloprost during admission for her third course of cyclophosphamide the change in therapy was made following a thorough evaluation. Further improvement, demonstrated by normal RV function and no clinical signs of active SLE, was seen at 20 weeks (August 2014), when the patient was admitted for her fifth course of cyclophosphamide. At this point, the patient was reclassified as WHO FC I. The patient has been stable on combination therapy from this time through to the present day.

\section{Commentary}

In patients with $\mathrm{PAH}$, right heart failure can be defined as a complex clinical syndrome arising from suboptimal delivery of blood and elevated systemic venous pressure at rest or during exercise due to increased RV afterload [8]. The key clinical symptoms of right heart failure are fluid retention and exercise limitation [8]. However, recognition of RV failure in the patient is not always straightforward. For example, RV failure can present with signs of backward heart failure (including enlarged neck veins, a swollen abdomen, ascites and oedema), but also symptoms of forward failure such as drowsiness, peripheral cyanosis, hypotension and decreasing diuresis, with forward failure symptoms being frequently underestimated in clinical practice $[9,10]$.

When monitoring for RV failure, it is important to note that evaluation of vital signs, ECG and laboratory parameters is essential to gauge cardiac and end-organ function [9]. Similar to observations in the presented patient case, clinical signs of concern in a patient with RV failure are decreased diuresis, elevated lactate and/or reduced $\mathrm{S}_{\mathrm{VO}_{2}}$. As a marker of tissue oxygenation, and because it correlates very well both with cardiac output and central venous oxygen saturation, $\mathrm{SvO}_{2}$ can serve as a guide, in part, to the success of subsequent treatment strategies [9].

Guidance on the appropriate management of acute right heart failure in intensive care has been relatively sparse, particularly in complex cases such as the one presented here. A treatment algorithm has been proposed for managing right heart failure based on available evidence and physiological principles [9]. This algorithm, which served as a general guide for the management of the current patient case, aims to compensate for RV failure using six different treatment strategies that can be followed concurrently rather than sequentially: 1) treat triggering factors (in this patient, SLE was the triggering factor that required treatment); 2) optimise fluid balance; 3) reduce RV afterload; 4) optimise cardiac output; 5) optimise perfusion pressure; and 6) consider lung transplantation and extracorporeal life support [9]. Various treatments can be utilised together or in sequence in the right heart management pathway, a strategy that was followed in the current patient, including the recommended administration of i.v. diuretics to reduce excess fluid in step 2 [9]. In this patient case, i.v. furosemide was the selected diuretic, although the algorithm also includes haemofiltration as an alternative strategy for reducing excess fluid [9]. A negative fluid balance is almost always a key mediator of treatment success, but fluid challenge requires careful monitoring to avoid reducing the existing low cardiac output status and therefore further impairing end-organ function [9]. Another important means of reversing RV failure is the reduction of RV afterload, which may be achieved in step 3 of the algorithm using i.v. prostanoids (iloprost was used in this patient case) as the treatment of choice in treatment naïve and previously non-i.v. treated patients with $\mathrm{PAH}$, or 
inhaled vasodilators, especially in those who are intolerant to i.v. prostanoids [9]. Treatments that have shown promising results as up-front triple combination therapy in patients with severe PAH include oral endothelin receptor antagonists and phosphodiesterase type 5 inhibitors, such as the macitentan and sildenafil administered to this patient [11]. Due to restoration of cardiac output under reduced afterload, the problem of hypotension often improves using this approach. Hence, in this patient, up-front triple-combination therapy was used. With enhancing effects on myocardial contractility and reduction of right and left ventricular afterload, the $\beta 1$-agonist dobutamine is the preferred catecholamine in the treatment of RV failure and is recommended in step 4 of the pathway to optimise cardiac output. Dobutamine was given as part of the management strategy for the current patient case, but non-chronotropic agents such as phosphodiesterase type 3 inhibitors can be considered as an alternative in some patients at risk of tachycardia [9]. Although unnecessary for this patient, if steps 1-5 are unsuccessful in treating right heart failure, the algorithm culminates with a bridging strategy until lung or heart-lung transplantation is possible [9]. Technological advances have led to an increase in the use of extracorporeal life support as a preferred bridging strategy [9]. In a published case series, the feasibility of veno-arterial extracorporeal membrane oxygenation as a bridge to lung transplantation was demonstrated in five awake and non-intubated patients with PH and RV failure, three of whom fully recovered after transplantation [12].

Immunosuppressive therapy is recommended as part of PAH disease management to treat the underlying inflammation implicated in connective tissue disease-associated PAH, including SLE and mixed connective tissue disease $[4,13]$. Although there is a lack of published randomised controlled trials solely enrolling patients with PAH and SLE, immunosuppressive therapy with high-dose glucocorticoids plus cyclophosphamide has shown efficacy, as measured by functional class, exercise capacity and haemodynamic function, in retrospective studies of PAH in SLE $[14,15]$. Immunosuppressive therapy alone is not sufficient in patients with SLE and severe haemodynamic impairment, for whom immediate immunosuppression together with PAH treatment is recommended [9]. Evidence supporting the benefits of combining immunosuppressive therapy with PAH treatments in SLE and mixed connective tissue disease-associated PAH is largely drawn from retrospective studies and case reports $[15,16]$. One case study of a patient with severe PAH associated with mixed connective tissue disease recently reported clinical improvement following the introduction of initial triple combination PAH therapy in the form of i.v. epoprostenol, bosentan and tadalafil combined with immunosuppressive therapy (oral corticosteroids and i.v. cyclophosphamide) [16]. Moreover, it has been shown that a maintenance regimen of immunosuppression and PAH therapy in combination confers favourable effects on pulmonary haemodynamics and the long-term prognosis of patients with connective tissue disease-associated PAH [17]. Collectively, these reports lend support to the initial strategy of immunosuppressive therapy and triple-combination $\mathrm{PAH}$ treatment that was implemented for this patient who was subsequently maintained on a regimen of cyclophosphamide and double-combination PAH therapy.

In the current case, the decision to change from triple to double-combination PAH therapy was made after the patient developed a fever associated with the indwelling central venous catheter for i.v. iloprost. Catheter-related infections from i.v. prostacyclin use have been reported in patients with PAH, who may experience treatment noncompliance and impaired quality of life (QoL) as a result of adverse effects as well as the inconvenience of this mode of treatment [18-24]. In this patient, withdrawal of i.v. iloprost and continued treatment with the combined oral PAH therapy of macitentan and sildenafil was associated with clinical improvement, and may have contributed to improved satisfaction and QoL. However, in general, downscaling of therapy from triple- to double-combination therapy cannot be recommended for patients with PAH. In this patient, adequate treatment of the underlying disease led to a regression of the PAH that allowed this approach. Close follow-up is essential in this setting.

In summary, this case demonstrates that, in the management of severe PAH with right heart failure, it is imperative that the underlying causes of RV failure are identified and treated by appropriate monitoring (especially volume status), use of inotropes/vasopressors if necessary, and initiation of aggressive triple combination PAH therapy. Effective control of SLE can result in improvement and, in some cases, regression of $\mathrm{PAH}$.

\section{Case 2}

A rare case of $\mathrm{PH}$ associated with pulmonary veno-occlusive disease

The diagnosis and treatment of pulmonary veno-occlusive disease (PVOD) presents a challenge to the practising clinician, primarily because the condition remains poorly understood and is difficult to distinguish from idiopathic PAH (IPAH) [25-27]. It is estimated that PVOD accounts for $5-10 \%$ of cases initially misdiagnosed as IPAH $[25,28]$.

In September 2011, a 48-year-old female, who was an active smoker, presented to the centre with dyspnoea. She had a prior history of a minor stroke (in 2007) resulting from dissection of the intracranial carotid artery for which she received oral anticoagulation therapy. Several years later, in 2010, the onset of 
exercise dyspnoea was documented, but further investigations were not undertaken until 6 months later when the patient's dyspnoea worsened. At that time, an ECG revealed increased systolic pulmonary arterial pressure $(53 \mathrm{mmHg})$, and a contrast-enhanced CT scan identified a distal pulmonary embolism. After referral to our centre and on initial physical examination, a WHO FC III status was recorded together with observations of normal weight, a normal heart rate of 70 beats. $\mathrm{min}^{-1}$ and systemic oxygen saturation at rest of $95 \%$. There was no indication of right heart failure, although additional results from the physical examination noted a systolic murmur on the left parasternal border.

Subsequent work-up was undertaken according to the current recommended diagnostic approach for $\mathrm{PH}$, which follows a stepwise process of invasive and noninvasive techniques, from ECG, ventilation/perfusion scintigraphy and RHC to specific diagnostic tests, to differentiate a suspected condition from PAH [29]. Consistent with the algorithm, the patient underwent chest radiography and ECG, the results of which showed RV enlargement and excluded congenital heart disease. Bilateral small peripheral nonsegmental defects in perfusion detected by a subsequent perfusion lung scan were not verified by contrast-enhanced CT and pulmonary angiography. Furthermore, high-resolution CT (HRCT) excluded parenchymal lung disease (fig. 2a). Additional results from arterial blood gas analysis identified reduced diffusing capacity of the lungs for carbon monoxide (DLCO) (53\% of the theoretical value) and decreased partial oxygen pressure $(60 \mathrm{mmHg})$, while haemodynamic parameters obtained from RHC confirmed pre-capillary PAH and no right heart failure (table 2). Notably, nitric oxide inhalation performed during RHC did not meet the criteria for an acute vasoreactivity response. Differential diagnoses of HIV, hepatitis B and C virus, thrombophilia, thyroid disorders and heritable PAH were excluded by laboratory tests.

The patient was discharged in October 2011 with a diagnosis of IPAH and WHO FC III status, and received bosentan $62.5 \mathrm{mg}$ twice daily for the first month and $125 \mathrm{mg}$ twice daily thereafter, furosemide (25 $\mathrm{mg}$ once daily), warfarin and canrenone (50 mg once daily). Examination after 6 months showed an improvement to WHO FC II and corresponding improvements in exercise capacity and haemodynamic parameters (table 2). The patient's condition remained stable until 2 years post-diagnosis when tadalafil $40 \mathrm{mg}$ once daily was introduced in combination with bosentan $125 \mathrm{mg}$ twice daily in response to a deterioration to WHO FC III, reduced exercise capacity and worsened haemodynamic parameters on RHC (table 2). The patient was discharged from the centre in November 2014. There was no clinical
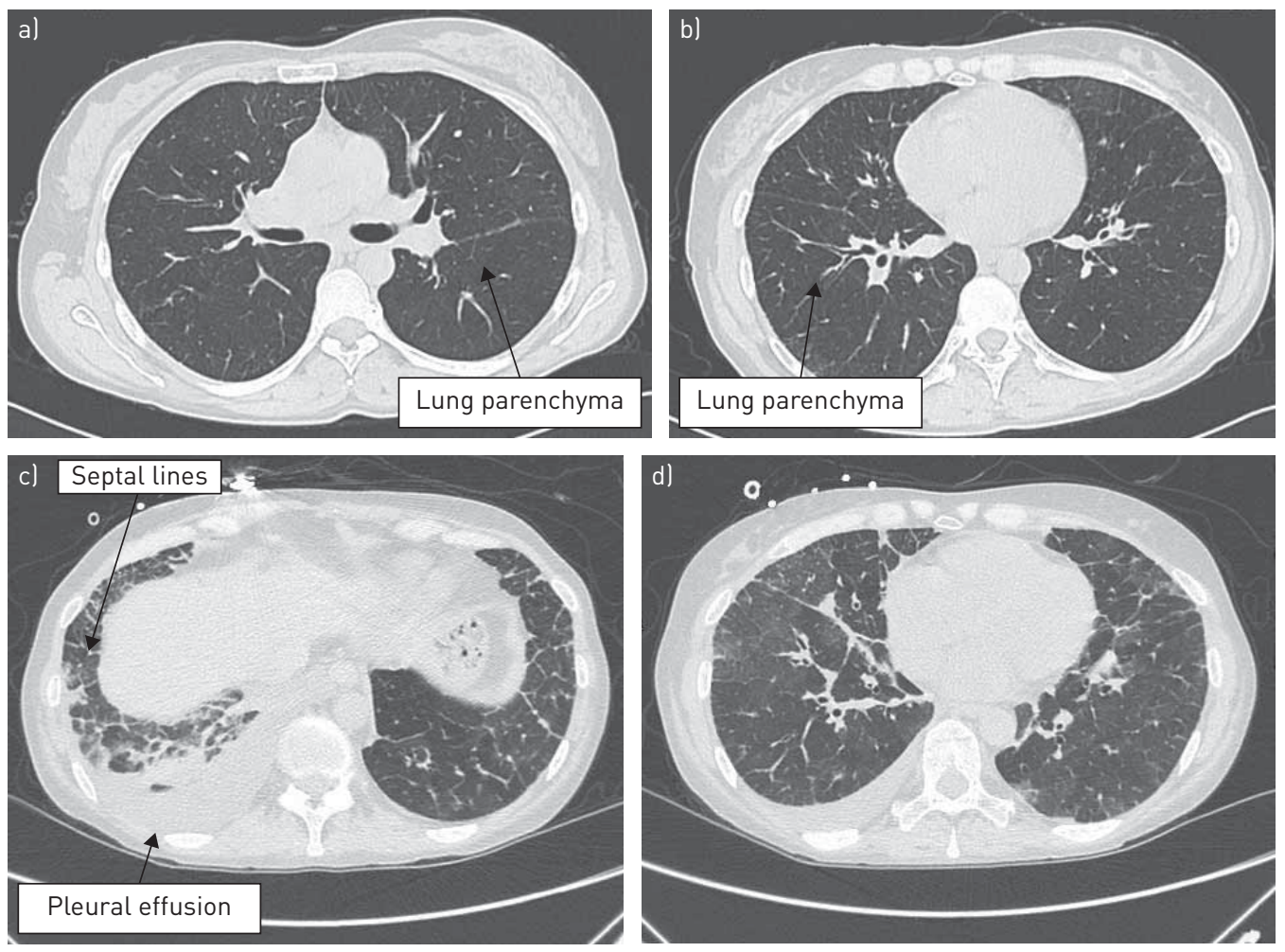

FIGURE 2 High-resolution computed tomography scans during diagnostic evaluation in a patient with pulmonary veno-occlusive disease, which had been previously diagnosed as idiopathic pulmonary arterial hypertension, showing no evidence of parenchymal disease in $a, b)$ two different slices and $c, d$ ) illustrating diffuse ground-glass opacities with thickening interlobular septa (case study 2). 
TABLE 2 RHC parameters, exercise capacity, and WHO FC status before and after treatment in a patient with PVOD (case study 2)

Measurement

\begin{tabular}{cccc}
\hline $\begin{array}{c}\text { Baseline } \\
\text { (September 2011) }\end{array}$ & April 2012 & November 2014 & March 2015
\end{tabular}

\begin{tabular}{|c|c|c|c|c|}
\hline Heart rate beats $\cdot \min ^{-1}$ & 70 & 67 & 72 & 88 \\
\hline Right atrial pressure $\mathrm{mmHg}$ & 4 & 4 & 4 & 3 \\
\hline Systolic/diastolic/mean PAP mmHg & $56 / 19 / 36$ & $41 / 17 / 25$ & $55 / 24 / 37$ & $40 / 20 / 29$ \\
\hline PCWP mmHg & 12 & 13 & 13 & 13 \\
\hline Cardiac index $\mathrm{L} \cdot \mathrm{min}^{-1} \cdot \mathrm{m}^{-2}$ & 2.4 & 3.1 & 3.4 & 4.0 \\
\hline PVR Wood units & 5.9 & 2.3 & 4.4 & 2.7 \\
\hline SVR Wood units & 22.2 & 14.8 & 13.5 & 12.8 \\
\hline 6MWD m & 473 & 558 & 470 & $\S$ \\
\hline WHO FC & III & II & III & III/IV \\
\hline \multicolumn{5}{|c|}{$\begin{array}{l}\text { RHC: right heart catheterisation; WHO FC: World Health Organization functional class; PVOD: pulmonary veno-occlusive disease; PAP: pulmonary } \\
\text { arterial pressure; PCWP: pulmonary capillary wedge pressure; PVR: pulmonary vascular resistance; SVR: systemic vascular resistance; } 6 \mathrm{MWD} \text { : } \\
\text { 6-min walking distance. " }{ }^{\#} \text { : treatments at the time of measurement were bosentan } 125 \mathrm{mg} \text { twice daily, furosemide } 25 \mathrm{mg} \text { once daily, warfarin and } \\
\text { canrenone } 50 \mathrm{mg} \text { once daily; }{ }^{\uparrow}: \text { treatments at the time of measurement were bosentan } 125 \mathrm{mg} \text { twice daily, furosemide } 25 \mathrm{mg} \text { once daily, warfarin } \\
\text { and canrenone } 50 \mathrm{mg} \text { once daily; }{ }^{+} \text {: treatments at the time of measurement were bosentan } 125 \mathrm{mg} \text { twice daily, tadalafil } 20 \mathrm{mg} \text { once daily and } \\
\text { oxygen; }{ }^{\S} \text { : the patient was unable to walk and therefore the test was not performed. }\end{array}$} \\
\hline
\end{tabular}

improvement following initiation of combination therapy and in January 2015 she was admitted to the local hospital due to worsening of symptoms. At this time, she commenced antibiotics and oxygen therapy due to a suspected lung infection. However, despite a slight improvement, the patient was readmitted in February 2015 with respiratory failure, which was diagnosed at the patient's local hospital, and for which she was administered a second course of antibiotics. The patient was referred again to our centre in March 2015 after clinical deterioration, as evidenced by a WHO FC III-IV status. Although no right heart failure or peripheral oedema was evident, pleural effusion was apparent and the severity of her condition incapacitated the patient to such a degree that she was unable to walk. Laboratory tests performed at this time excluded the presence of infections. Subsequently, HRCT (fig. 2b) and bronchoalveolar lavage (which identified alveolar haemorrhage) confirmed PVOD. As a result, furosemide (i.v.) was initiated at a dose of $40 \mathrm{mg} \cdot \mathrm{day}^{-1}$ and tadalafil was withdrawn, which was associated with symptom improvement. Consequently, the patient was discharged in March 2015 with a diagnosis of PVOD in WHO FC III. At discharge, the patient continued to receive bosentan $125 \mathrm{mg}$ twice daily, high-dose furosemide $50 \mathrm{mg}$ twice daily, canrenone $50 \mathrm{mg}$ once daily and oxygen therapy $2 \mathrm{~L} \cdot \mathrm{day}^{-1}$. Lung transplantation is currently being considered for this patient.

\section{Commentary}

PVOD is a disease characterised by progressive occlusion of small pulmonary veins leading to an increase in PVR and RV failure that confers a life expectancy of $<2$ years without treatment [26].

As demonstrated in this patient case, correctly distinguishing PVOD from clinically similar conditions underpins appropriate diagnosis and optimal management of the disease, which ultimately impacts on the potential to improve survival outcomes. PVOD bears a similarity to $\mathrm{PAH}$, which is recognised and reflected in the WHO classification system for PH [30]. Thus, all disorders related to PAH are classified within group 1 (PAH) of the WHO classification system, with PVOD categorised as a subgroup of group 1 [30]. However, despite this similarity, there are distinctive clinical, genetic, environmental and phenotypic features that differentiate PVOD from PAH subtypes such as IPAH, including predisposing factors $[25,26,31,32]$. Recently, genetic studies have shown that PVOD occurs sporadically or is inherited in families due to recessive mutations of the eukaryotic translation initiation factor 2 alpha kinase 4 (EIF2AK4) gene which encodes the GCN2 protein [31]. In addition, environmental factors such as a heavier smoking habit (greater tobacco exposure) have been reported to occur at a higher frequency in PVOD than in IPAH patient populations $[25,33]$. At a clinical level, the haemodynamic presentation of PVOD is similar to IPAH, particularly with respect to wedge pressure, which is invariably normal in both disease conditions [33]. However, patients with PVOD are more severely hypoxaemic and have a markedly lower DLCO than other forms of PAH [33]. The presence of these defining clinical characteristics of PVOD was clearly evident in the patient described here, who was a smoker and therefore potentially predisposed to developing PVOD. 
Differentiating PVOD from PAH based on clinical observation alone is generally unfeasible because both conditions cause overlapping nonspecific symptoms of dyspnoea, exercise limitation, fatigue and syncope [26, 28]. Instead, as in this patient, the diagnosis of PVOD can be established with high probability using a combined approach of clinical suspicion, physical examination, RHC, pulmonary function tests, bronchoscopy with bronchoalveolar lavage, and radiological findings [25, 26, 34]. Preferred tests for diagnosing PVOD are HRCT and bronchoalveolar lavage along with assessment of partial pressure of oxygen and DLCO [25, 35, 36], all of which were used in the diagnostic work-up for this patient case. HRCT, in particular, is an important diagnostic modality that differentiates PVOD from IPAH with high sensitivity and specificity based on the presence of a triad of ground-glass opacities (centrilobular pattern, thickened interlobular septa and mediastinal lymphadenopathy) in PVOD [25, 34]. Bronchoalveolar lavage may be employed to detect signs of haemosiderin-laden macrophages and occult alveolar haemorrhage [25]. While evidence is less definitive in the use of bronchoalveolar lavage, preliminary studies support the diagnostic utility of the technique in identifying occult alveolar haemorrhage in patients with PVOD [25].

Once diagnosed, the treatment options for PVOD are limited, which contributes to the poor prognosis for this patient population. In patients with PVOD, the potential exists for development of pulmonary oedema or poor treatment response with administration of $\mathrm{PAH}$ therapies, which is a further differentiating feature of PVOD from PAH $[25,26]$. Nevertheless, cautious use of PAH therapy may impart some benefit and serve as a bridge to lung or combined heart-lung transplantation, which is the treatment of choice in patients with PVOD $[25,26,37]$. In this patient case, the cautious introduction of bosentan (titrated over a month) in combination with a therapeutic regimen that included high-dose diuretics was associated with some degree of clinical benefit, thereby enabling the patient to be considered for lung transplantation. The approach adopted for this patient is supported by a retrospective review of 12 patients with PVOD, in which administration of i.v. epoprostenol at low-dose ranges (with slow dose increments) together with high-dose diuretics was associated with improvements in WHO FC (from IV to III) and exercise capacity, and a decrease in PVR [37].

This case clearly illustrates that PVOD remains a challenging disease entity from both a diagnostic and a therapeutic perspective.

\section{General conclusion}

This case-based review brings to light the existence of challenging forms of $\mathrm{PH}$ in the clinical setting: new-onset PAH with right heart failure and active SLE, and PVOD. Continuous follow-up of these patients, together with a regular, individual assessment of treatment success and/or a critical re-evaluation of the diagnosis is essential. The management of these conditions merits greater consideration and attention in clinical practice recommendations.

\section{Acknowledgements}

The authors would like to thank Anusha Bolonna from PAREXEL (Worthing, UK) for medical writing assistance, funded by Actelion Pharmaceuticals Ltd (Allschwil, Switzerland).

\section{References}

1 Galiè N, Humbert M, Vachiery JL, et al. 2015 ESC/ERS Guidelines for the diagnosis and treatment of pulmonary hypertension. Eur Heart J 2015 [In press DOI: 10.1093/eurheartj/ehv317].

2 Galiè N, Humbert M, Vachiery JL, et al. 2015 ESC/ERS Guidelines for the diagnosis and treatment of pulmonary hypertension. Eur Respir J 2015; 46: 903-975.

3 Dhala A. Pulmonary arterial hypertension in systemic lupus erythematosus: current status and future direction. Clin Dev Immunol 2012; 2012: 854941.

4 Condliffe R, Howard LS. Connective tissue disease-associated pulmonary arterial hypertension. F1000Prime Rep 2015; 7: 06

5 Winslow TM, Ossipov MA, Fazio GP, et al. Five-year follow-up study of the prevalence and progression of pulmonary hypertension in systemic lupus erythematosus. Am Heart J 1995; 129: 510-515.

6 Prabu A, Patel K, Yee CS, et al. Prevalence and risk factors for pulmonary arterial hypertension in patients with lupus. Rheumatology (Oxford) 2009; 48: 1506-1511.

7 Simonson JS, Schiller NB, Petri M, et al. Pulmonary hypertension in systemic lupus erythematosus. J Rheumatol 1989; 16: 918-925.

8 Vonk-Noordegraaf A, Haddad F, Chin KM, et al. Right heart adaptation to pulmonary arterial hypertension: physiology and pathobiology. J Am Coll Cardiol 2013; 62: Suppl., D22-D33.

9 Hoeper MM, Granton J. Intensive care unit management of patients with severe pulmonary hypertension and right heart failure. Am J Respir Crit Care Med 2011; 184: 1114-1124.

10 Price LC, Wort SJ, Finney SJ, et al. Pulmonary vascular and right ventricular dysfunction in adult critical care: current and emerging options for management: a systematic literature review. Crit Care 2010; 14: R169.

11 Sitbon O, Jais X, Savale L, et al. Upfront triple combination therapy in pulmonary arterial hypertension: a pilot study. Eur Respir J 2014; 43: 1691-1697.

12 Olsson KM, Simon A, Strueber M, et al. Extracorporeal membrane oxygenation in nonintubated patients as bridge to lung transplantation. Am J Transplant 2010; 10: 2173-2178.

13 Takeuchi K, Watanabe H. Pulmonary arterial hypertension associated with connective tissue disease and immunosuppressive therapy. Circ J 2011; 75: 2543-2544. 
14 Sanchez O, Sitbon O, Jais X, et al. Immunosuppressive therapy in connective tissue diseases-associated pulmonary arterial hypertension. Chest 2006; 130: 182-189.

15 Jais $\mathrm{X}$, Launay $\mathrm{D}$, Yaici A, et al. Immunosuppressive therapy in lupus- and mixed connective tissue disease-associated pulmonary arterial hypertension: a retrospective analysis of twenty-three cases. Arthritis Rheum 2008; 58: 521-531.

16 Sitbon O, Bertoletti L. Connective tissue disease associated with pulmonary arterial hypertension: management of a patient with severe haemodynamic impairment. Eur Respir Rev 2014; 23: 505-509.

17 Miyamichi-Yamamoto S, Fukumoto Y, Sugimura K, et al. Intensive immunosuppressive therapy improves pulmonary hemodynamics and long-term prognosis in patients with pulmonary arterial hypertension associated with connective tissue disease. Circ J 2011; 75: 2668-2674.

18 de Jesus Perez VA, Rosenzweig E, Rubin LJ, et al. Safety and efficacy of transition from systemic prostanoids to inhaled treprostinil in pulmonary arterial hypertension. Am J Cardiol 2012; 110: 1546-1550.

19 Shafazand S, Goldstein MK, Doyle RL, et al. Health-related quality of life in patients with pulmonary arterial hypertension. Chest 2004; 126: 1452-1459.

20 de Lartigue J. Oral treprostinil for the treatment of pulmonary arterial hypertension. Drugs Today (Barc) 2014; 50: 557-565.

21 Oudiz RJ, Widlitz A, Beckmann XJ, et al. Micrococcus-associated central venous catheter infection in patients with pulmonary arterial hypertension. Chest 2004; 126: 90-94.

22 Rival G, Lacasse Y, Martin S, et al. Effect of pulmonary arterial hypertension-specific therapies on health-related quality of life: a systematic review. Chest 2014; 146: 686-708.

23 US Food and Drug Administration (FDA). The voice of the patient. A series of reports from the U.S. Food and Drug Administration's (FDA's) patient-focused drug development initiative. Pulmonary arterial hypertension. www.fda.gov/downloads/ForIndustry/UserFees/PrescriptionDrugUserFee/UCM429382.pdf Date last accessed: August 17, 2015. Date last updated: December, 2014

24 Lang IM, Gaine SP. Recent advances in targeting the prostacyclin pathway in pulmonary arterial hypertension. Eur Respir Rev 2015; 24: 630-641.

25 Dai Z, Matsui Y. Pulmonary veno-occlusive disease: an 80-year-old mystery. Respiration 2014; 88: 148-157.

26 Montani D, O'Callaghan DS, Savale L, et al. Pulmonary veno-occlusive disease: recent progress and current challenges. Respir Med 2010; 104: Suppl. 1, S23-S32.

27 Mandel J, Mark EJ, Hales CA. Pulmonary veno-occlusive disease. Am J Respir Crit Care Med 2000; 162: 1964-1973.

28 Huertas A, Girerd B, Dorfmuller P, et al. Pulmonary veno-occlusive disease: advances in clinical management and treatments. Expert Rev Respir Med 2011; 5: 217-229.

29 Hoeper MM, Bogaard HJ, Condliffe R, et al. Definitions and diagnosis of pulmonary hypertension. J Am Coll Cardiol 2013; 62: Suppl., D42-D50.

30 Simonneau G, Gatzoulis MA, Adatia I, et al. Updated clinical classification of pulmonary hypertension. J Am Coll Cardiol 2013; 62: Suppl., D34-D41.

31 Eyries M, Montani D, Girerd B, et al. EIF2AK4 mutations cause pulmonary veno-occlusive disease, a recessive form of pulmonary hypertension. Nat Genet 2014; 46: 65-69.

32 Palazzini M, Manes A. Pulmonary veno-occlusive disease misdiagnosed as idiopathic pulmonary arterial hypertension. Eur Respir Rev 2009; 18: 177-180.

33 Montani D, Achouh L, Dorfmuller P, et al. Pulmonary veno-occlusive disease: clinical, functional, radiologic, and hemodynamic characteristics and outcome of 24 cases confirmed by histology. Medicine (Baltimore) 2008; 87: 220-233.

34 Mineo G, Attina D, Mughetti M, et al. Pulmonary veno-occlusive disease: the role of CT. Radiol Med 2014; 119: 667-673.

35 Resten A, Maitre S, Humbert M, et al. Pulmonary hypertension: CT of the chest in pulmonary venoocclusive disease. AJR Am J Roentgenol 2004; 183: 65-70.

36 Rabiller A, Jais X, Hamid A, et al. Occult alveolar haemorrhage in pulmonary veno-occlusive disease. Eur Respir J 2006; 27: 108-113.

37 Montani D, Jais X, Price LC, et al. Cautious epoprostenol therapy is a safe bridge to lung transplantation in pulmonary veno-occlusive disease. Eur Respir J 2009; 34: 1348-1356. 